\title{
Noticias
}

\section{Conferencias, congresos y Jornadas}

\subsection{Conferencias}

Se han celebrado varias Jornadas en el Grado CCAFYDE dirigidas a la formación de nuestro estudiantado en relación con sus salidas profesionales en los diferentes itinerarios que conforman el Grado.

El Decanato de Medicina y Ciencias de la Salud y el Vicedecanato de Ciencias de la Actividad Física y del Deporte, organizaron, el pasado 5 de marzo el 'I Encuentro Egresados CCAFYDEUAH', un espacio destinado al intercambio de impresiones y experiencias de antiguos estudiantes del Grado Ciencias de la Actividad Física y del Deporte de la UAH de diferentes ámbitos profesionales ligados al deporte. La reunión está dirigida a todo el estudiantado interesado en profundizar en las distintas salidas profesionales adscritas a este Grado desde la visión de los AlumniUAH que ya se

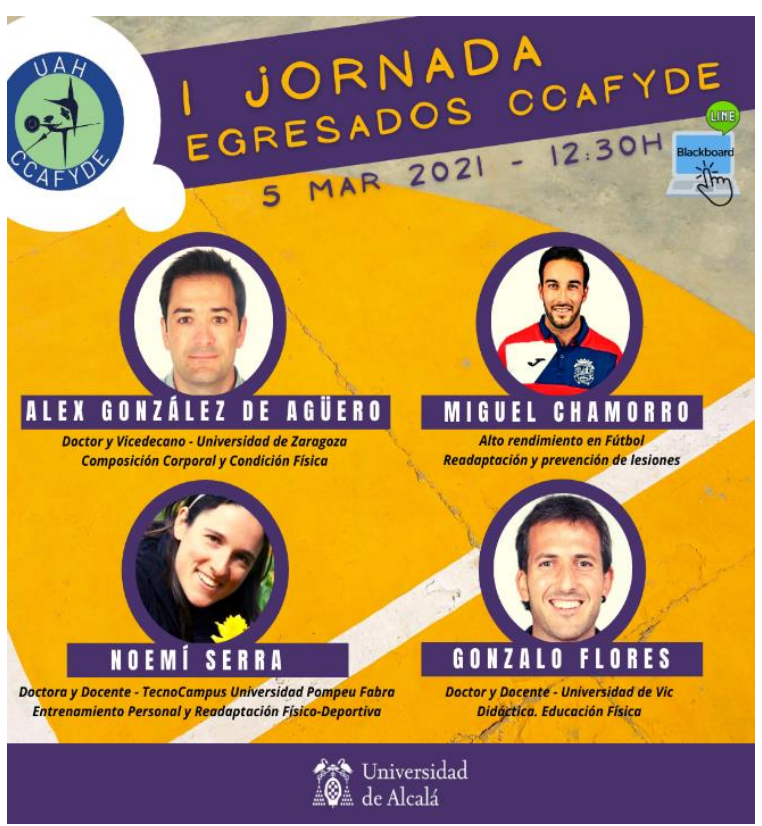
encuentran en el mercado laboral dedicándose no solo a la enseñanza sino a la composición corporal y condición física, al alto rendimiento en distintos deportes, al entrenamiento personal y la readaptación físico-deportiva o la didáctica de la educación física.

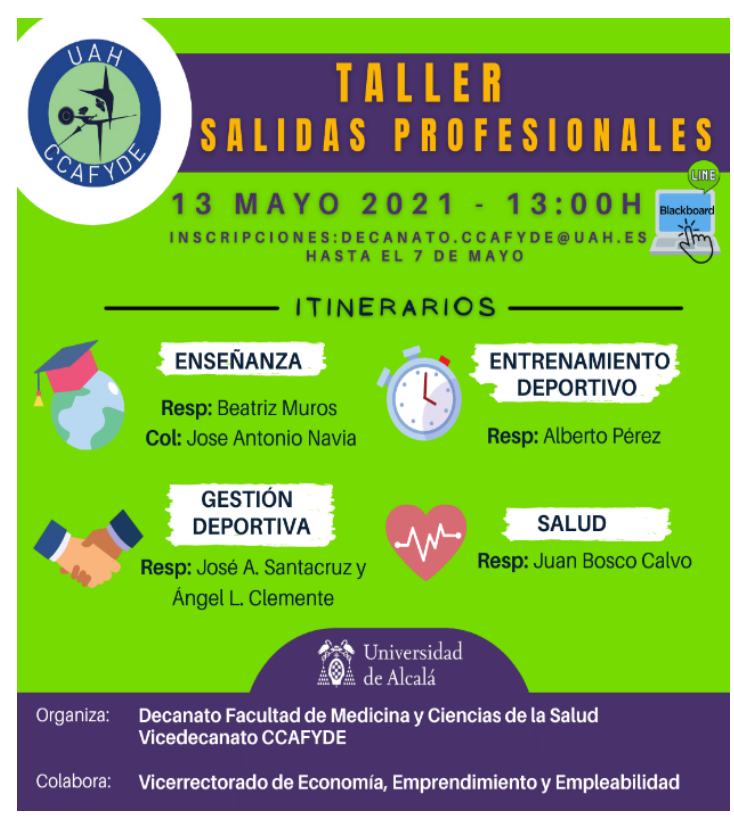

Como continuación a tal iniciativa, se organizó el I Taller sobre salidas profesionales. En esta ocasión se contó, desde el Decanato de Medicina y Ciencias de la Salud y el Vicedecanato de Ciencias de la Actividad Física y del Deporte, con profesorado del Grado para llevar a cabo el taller. Colabora el Vicerrectorado de Economía, Emprendimiento y Empleabilidad 
En el Grado de Enfermería se han celebrado:

- JORNADA “SALIDAS PROFESIONALES Y FORMACIÓN POSTGRADO” 15 de enero de 2021 para el Grado en Enfermería a través del Aula Virtual en la Sala del curso TFG donde se les informa de las distintas salidas laborales, el EIR y la formación postgrado.

- JORNADA “SALIDAS PROFESIONALES Y FORMACIÓN POSTGRADO” 15 de enero de 2021 para el Grado en Enfermería Guadalajara a través del Aula Virtual en la Sala del curso TFG donde se les informa de las distintas salidas laborales, el EIR y la formación postgrado.

En el Grado de Fisioterapia,

- Del 9 al 11 de abril se celebró una nueva edición de la Confederación Mundial de Fisioterapia. Destacar la participación de alumnos y profesores de los estudios de Grado en Fisioterapia con la presentación de varios trabajos de investigación.

- El pasado 20 de mayo se publicó el ranking de mejores universidades españolas. Este año, la Universidad de Alcalá y sus estudios de Grado de Fisioterapia, dentro de la Facultad de Medicina y Ciencias de la Salud, aparece en primer lugar.

\section{Actividades Culturales}

\subsection{Libros}

- Capítulo de libro: Blázquez, D. \& Flores, G. (2020). Gamificación Educativa GE (p.297-325). En D. Blázquez (Eds.) Métodos de enseñanza en educación física. Enfoques innovadores para la enseñanza de competencias (3aㅡ Edición). Barcelona: INDE.

- Jean Noël Fabiani y Philippe Bercovici publican el cómic "La increíble Historia de la Medicina" en la Editorial Norma (ISBN: 978-84-679-4396-2). Un libro ilustrado sobre la Historia de una disciplina que ha acompañado a los grandes movimientos del pensamiento y que penetra en las guerras y la política de su tiempo. Plagado de anécdotas que había que contar e ilustrar y que son a la vez serias y divertidas.

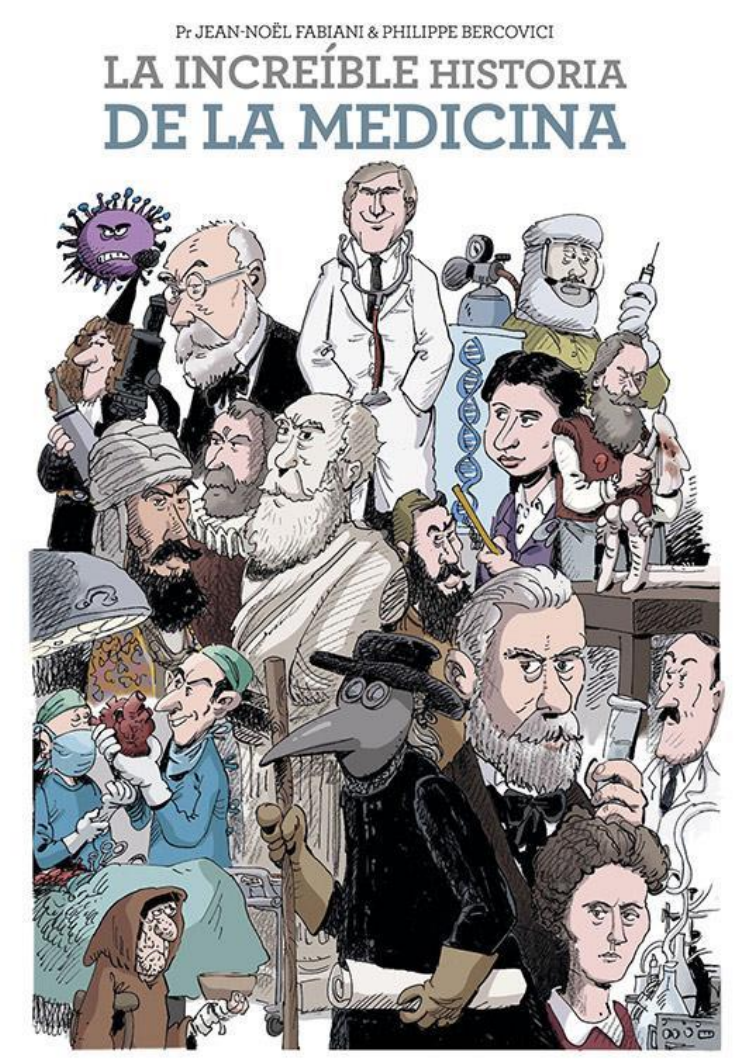


- Publicación de "COVID-19. Un enfoque plural", primer volumen de la colección "Miradas UAH" de la editorial de la Universidad de Alcalá (UAH). Puede verse la noticia completa en el Portal de Comunicación de la UAH, y el vídeo de la presentación del libro en el Paraninfo de la Universidad, en el canal de la Universidad en YouTube.

\subsection{Teatro}

El Grupo de Teatro de la Facultad de Medicina y Ciencias de la Salud, representó el día 27 de abril la obra de teatro "Knives out", traducido en castellano como "Puñales por la espalda" en España y, "Entre navajas y secretos" en Hispanoamérica, es una película de misterio estadounidense de 2019 escrita y dirigida por Rian Johnson y producida por Johnson y Ram Bergman. Al más puro estilo Agatha Christie, la trama refiere una reunión familiar en la que se produce la muerte del patriarca, el mismo día de su 85 cumpleaños. Un detective un poco especial investigará a la familia, hasta descubrir el asesinato y al asesino.

La película ha sido ampliamente reconocida y premiada, recibiendo tres nominaciones en la categoría de Musical o Comedia, nominaciones a Mejor Guion Original y seleccionada como una de las diez mejores películas de 2019. En este caso, el Grupo de Teatro de la Facultad de Medicina y Ciencias de la Salud, representa de manera telemática está obra, adaptándola a las condiciones de la actual pandemia. La obre puede visionarse en el enlace:

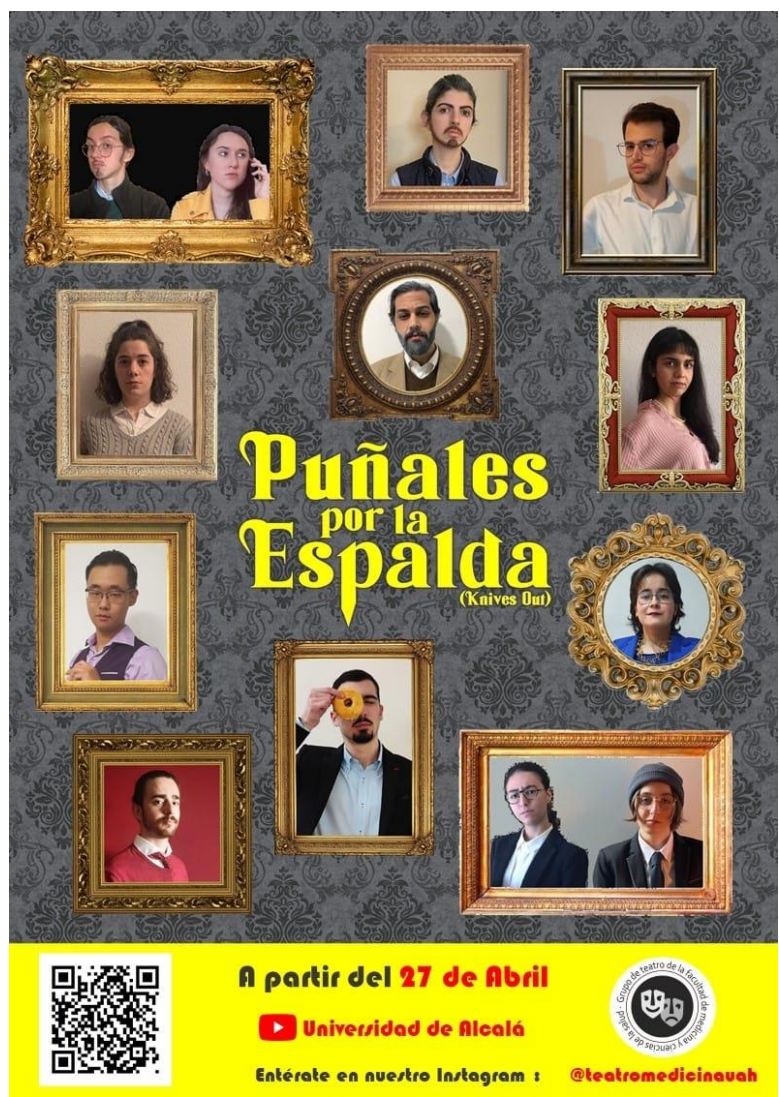
https://youtu.be/B9Rlg7WjkUw

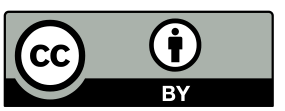

(C) 2021 por los autores; Esta obra está sujeta a la licencia de Reconocimiento 4.0 Internacional de Creative Commons. Para ver una copia de esta licencia, visite http://creativecommons.org/licenses/by-nc-nd/4.0/. 